\title{
Feminismo, identidade e exclusão política em Judith Butler e Nancy Fraser ${ }^{1}$
}

Resumo: O objetivo deste artigo é apontar déficits normativos em Judith Butler, assim como pontos cegos no diagnóstico de Nancy Fraser. Com base em Fraser, sustento que Butler não pode justificar sua crítica à exclusão e nem tampouco diferenciar práticas mais ou menos opressoras em razão de um preconceito pós-estruturalista contra critérios normativos. De outro lado, com base em Butler, argumentarei que a recusa de Fraser em articular psicologia e política lhe deixa sem ferramentas para diagnosticar as ambiguidades da motivação da subordinação, em particular nos casos de injustiça de gênero.

Palavras-chave: J. Butler; N. Fraser; Feminismo; Teoria Crítica.

Feminism, identity and political exclusion in Judith Butler and Nancy Fraser

Abstract: This article aims to highlight Judith Butler's normative deficits as well as blind spots in Nancy Fraser's diagnosis. As far as the normative deficit is concerned, I rely on Fraser's claim that Butler could neither justify her critique of exclusion nor distinguish among more or less oppressive practices due to a poststructuralist prejudice against normative criteria. On the other hand, based on Butler's work, I point out that Fraser rejects the entanglement between politics and psychology, what leaves her with no tools to grasp the ambiguities in the motivations of subordination, especially when it comes to gender injustices.

Key Words: J. Butler; N. Fraser; Feminism; Critical Theory.

\footnotetext{
${ }^{1}$ Recebido em 05/02/2017 e aprovado em 18/03/2017.

2 Professora do departamento de Ciências Sociais da Universidade Federal de São Paulo (UNIFESP). Contato: ingridcy@gmail.com.
} 
| 248 |

Feminismo, identidade e exclusão política...

Feminismo, identidad y exclusión política en Judith Butler y Nancy Fraser

Resumen: El objetivo de este artículo es identificar déficits normativos en Judith Butler, así como "puntos ciegos" en el diagnóstico de Nancy Fraser. Con base en Fraser, sostengo que Butler no puede justificar su crítica a la exclusión ni diferenciar prácticas más o menos opresivas debido a un prejuicio posestructuralista contra criterios normativos. Por otra parte, con base en Butler, argüiré que la negativa de Fraser a combinar psicología y política la priva de herramientas para diagnosticar las ambigüedades de la motivación de la subordinación, particularmente en los casos de injusticia de género.

Palabras clave: J. Butler; N. Fraser; Feminismo; Teoría Crítica.

Na década de 1990, boa parte dos debates acadêmicos feministas circundaram o livro Problema de gênero: feminismo e a subversão da identidade de Judith Butler. Na filosofia política feminista não foi diferente. O livro de Butler trazia e ainda traz desafios, ideias ousadas e inquietações para autoras feministas que protagonizavam os debates sobre poder, autonomia, subjetivação, democracia e ação coletiva.

Nancy Fraser destaca-se entre essas protagonistas. Engajouse em inúmeras discussões com Butler, em cujo trabalho enxergou uma importante contribuição para articular uma crítica feminista à política de identidade, assim como para fazer o diagnóstico de opressão de gênero. No entanto, nessa mesma obra de Butler, Fraser identificou limitações relacionadas à sua recusa em articular os critérios normativos que estavam na base da formulação de seus diagnósticos. Mas para Fraser essas limitações poderiam ser superadas complementando-se o diagnóstico de Butler com a justificação de um critério normativo positivo. Essa tarefa, insistentemente recusada por Butler, poderia, segundo Fraser, ser assumida por ela mesma ou por outras teóricas críticas feministas (FRASER, 2011, 2014).

Mas a recusa de Butler em articular um critério normativo positivo não duraria muito. Seu trabalho da década de 2000 sofreu uma guinada que tem sido designada como "virada ética". Essa fase de seu pensamento trouxe importantes mudanças em sua 
concepção de política, reconhecimento e exclusão, mudanças decorrentes em grande medida da disposição de Butler em explicitar o critério normativo por trás de sua crítica à exclusão.

O propósito deste artigo, porém, não é discutir tais mudanças. O objetivo aqui é reconstituir o debate entre Butler e Fraser da década de 1990 sobre sujeito do feminismo e exclusão política. Embora essa discussão seja cronologicamente antiga na obra das autoras, ela não é teoricamente ultrapassada. Ao contrário, suas reflexões atuais reverberam as posições que tomaram em suas discussões em torno de Problema de gênero. Além disso, as eventuais inflexões em seus respectivos pensamentos também foram impactadas e até mesmo motivadas pelas críticas que dirigiram uma à outra nesse contexto. Por isso, considero que revisitar essa discussão contribui, de um lado, para trazer à tona as diferenças epistemológicas entre as autoras, diferenças estas que em seus trabalhos mais recentes estão apenas sugeridas; e, de outro lado, contribui para compreender as influências recíprocas que esse debate produziu no pensamento de cada uma delas.

No entanto, essas influências recíprocas não sugerem, a meu ver, uma complementaridade entre Butler e Fraser. Ao contrário de Fraser, considero que as fronteiras epistemológicas entre o feminismo pós-estruturalista e a teoria crítica feminista não é ultrapassável, ou ao menos não tão facilmente ultrapassável como Fraser acredita. ${ }^{3}$ Assim, ao trazer à tona os pontos cegos das autoras não pretendo saná-los pela combinação de seus argumentos, mas apenas explicitar, por meio de suas discussões, o que acredito que sejam déficits normativos em Butler, e déficits de diagnóstico em Fraser.

O primeiro argumento deste artigo é o de que o déficit normativo de Butler, na década de 1990, está relacionado a um preconceito pós-estruturalista em relação a critérios normativos, que os equipara invariavelmente a normas regulatórias. A primeira tarefa do artigo, portanto, será elucidar a diferença entre estes últimos por meio das críticas de Fraser a Butler.

${ }^{3}$ Discuto essa questão em Cyfer (2009).

Idéias, Campinas, SP, v.8, n.1, p. 247-274, jan/jun. 2017 
| 250 |

Feminismo, identidade e exclusão política...

O segundo argumento do artigo, por sua vez, é o de que o déficit de diagnóstico de Fraser está relacionado ao preconceito dela em relação à investigação da dimensão psíquica da motivação da subordinação. A autora evita deliberadamente oferecer diagnósticos que abordem esse aspecto da subordinação por considerar que estes estão na base da justificação de remédios políticos voltados para "reengenharias da consciência", que só reforçam o estigma que recai sobre grupos sociais vulneráveis. A segunda tarefa deste artigo, portanto, será a de justificar por que a exploração da vida psíquica do poder é indispensável para a produção de diagnóstico de injustiças sociais, em particular injustiças de gênero.

A primeira seção do artigo será dedicada a expor sinteticamente os principais argumentos de Problema de gênero, a obra que impulsiona os debates que serão analisados aqui. Em seguida, será discutida a obra A vida psíquica do poder, buscando-se salientar a concepção de crítica, resistência e reconhecimento ali articuladas.

Por fim, a terceira seção será dedicada a discutir a posição de Fraser em relação à dimensão ontológica e normativa do argumento de Butler em Problema de gênero de modo a explicitar as críticas de Fraser ao déficit normativo de Butler. Além disso, nessa mesma seção será retomada a relação entre política e psicologia em $A$ vida psíquica do poder com o objetivo de relacionar a dimensão ontológica do argumento de Butler, que Fraser subscreve, com a necessidade de explorar a vida psíquica do poder. Por meio dessa comparação, pretendo explicitar o que entendo como sendo um déficit de diagnóstico em Fraser.

\section{1) Judith Butler - identidade e exclusão}

Em Problema de gênero, Judith Butler teoriza a respeito da exclusão no interior do próprio movimento feminista relacionando-a ao discurso identitário que predominava no movimento feminista norte-americano até então. Seu principal 
ponto é o de que a identidade da mulher no movimento feminista, assim como qualquer outra, é reducionista e excludente, uma vez que não há características humanas suficientemente estáveis e abrangentes. Por isso, para a autora, as políticas de identidade não são permeáveis à multiplicidade de interesses e demandas dos integrantes do grupo que pretende representar (BUTLER, 2007, p. 34). Nessa perspectiva, uma das principais tarefas do feminismo é trazer à tona os conflitos que estiveram presentes na construção da identidade da mulher representada no movimento feminista.

Butler inspira-se no trabalho de Foucault, especialmente em História da sexualidade, no qual o autor sustenta que a principal marca da modernidade é o controle político sobre o corpo, uma consequência do fato de a conduta sexual ter se tornado um tema estrategicamente relevante à medida que a modernidade tornou o crescimento populacional uma questão política. Nesse contexto, a política gradativamente extrapola seus temas clássicos (como o fundamento do Estado e o modo correto de governar) para incluir também o controle e a classificação do corpo. Essa classificação, por sua vez, respalda-se em outro traço típico da modernidade, a ciência, responsável por estabelecer os critérios para distinguir o comportamento sexual sadio do doentio.

Foucault sustenta que na modernidade a ciência e o poder se misturaram até o ponto de se fundirem. Dessa fusão, emerge o que chama de "scientia sexualis", que constitui o sexo como objeto da verdade, que ordena, classifica e define procedimentos para produzir a verdade do sexo (FOUCAULT, 2005, p. 56). Mas essas normas, esse poder-saber, não apenas incidem ou reprimem o sujeito, elas o constituem. A ideia de Foucault, incorporada por Butler, é a de que o poder que se exerce sobre o corpo e o sexo:

não tem a forma da lei nem os efeitos da interdição [...], não fixa fronteiras para a sexualidade, provoca suas diversas formas, seguindo-as através de linhas de penetração infinitas. Não a exclui, mas inclui no corpo à guisa de modo de especificação dos indivíduos que cria a identidade do sujeito. Não procura esquivá-la, atrai suas variedades como espirais onde o prazer e 
| 252 |

Feminismo, identidade e exclusão política...

poder se reforçam. Não opõe barreira, organiza lugares de máxima saturação. Produz e fixa o despropósito sexual (FOUCAULT, 2005, p. 47).

Judith Butler aproveita essa concepção de norma para questionar o caráter científico e natural da mulher. Para ela, não basta compreender o gênero como uma construção social; é necessário também trazer à tona o caráter discursivo do próprio sexo (BUTLER, 1993, p. 23 e 2007, p. 33).

Seguindo Foucault, Butler afirma que o sexo não corresponde a uma superfície politicamente neutra sobre a qual a cultura incide, mas sim a um produto de discursos científicos que exprimem determinados interesses políticos e sociais. A concepção de sexo como um dado natural é um efeito da construção cultural de comportamentos esperados dos sujeitos. Assim, em Butler, tanto sexo quanto gênero são construções socioculturais, resultam da tentativa de os sujeitos se adequarem a regras sociais que constrangem a mulher a se comportar de modo "feminino", e o homem a agir de modo "masculino". É nesse sentido que Butler afirma que o gênero é performativo, ou seja, que o gênero é constituído por modos de agir associados à feminilidade e à masculinidade.

A norma disciplinar fundamental da identidade de gênero para Butler é a heteronormatividade, que estabelece a heterossexualidade como princípio regulatório da sexualidade. Uma das principais consequências da reiterada reprodução da performance da heteronormatividade é a ocultação do caráter político da norma disciplinar. De tanto ser repetida em toda parte, ela termina ganhando status de "natural" e, portanto, de "universal".

Se é a performance conforme a heteronormatividade que cria a ilusão de femininos e masculinos naturais, o locus da desconstrução da identidade "natural" será também a performance do sujeito. Mas, nesse caso, o comportamento do sujeito deverá confundir a correspondência entre desejo, sexo e gênero ao invés de confirmá-la. 
Em um mundo heteronormativo, as "drag queens" são subversivas justamente porque incitam essa confusão. As "drags" não modificam a representação do feminino; afinal, elas, ao contrário, reproduzem o feminino de modo completamente estereotipado. No entanto, sua performance da feminilidade é realizada por um corpo anatomicamente masculino. Assim, elas expõem publicamente a possibilidade de dissonância entre sexo, sexualidade e gênero, desestabilizando a fundamentação da identidade feminina e masculina na natureza. Essa desestabilização questiona as normas de gênero hegemônicas e torna o terreno das identificações mais instável e, por isso, mais permeável a performances subversivas.

a) A vida psíquica do poder e o reconhecimento

Reconhecimento é um tema que atravessa toda a obra de Butler. Desde seu primeiro livro Subjects of Desire: Hegelian Reflections in Twentieth Century in France, reconhecimento tem sido uma questão central em suas reflexões. Segundo a própria Butler, esse é o tema (e não gênero) que motiva e atravessa toda a sua obra. ${ }^{4}$

Na década de 1990, sua abordagem do reconhecimento será em grande medida motivada pelas críticas dirigidas a Problema de gênero, em particular por aquelas críticas que discutiam o problema da agência e da autonomia do sujeito produzido pelo poder. Essas críticas sugeriam que Butler havia criado uma armadilha para si mesma ao confiar em Foucault para fazer sua crítica à identidade. Assim, como Foucault, Butler foi acusada de "matar o sujeito", sua capacidade de ação, sua autonomia.

As primeiras respostas de Butler a essa crítica vieram em seu livro de 1993, Bodies that Matter, em grande parte dedicado a esclarecer e refinar seu conceito de performance. No entanto, em 1997, Butler admitirá que para avançar mais nessa resposta

\footnotetext{
${ }^{4}$ Entrevista de Judith Butler no documentário Judith Butler, philosophe en tout genre (2006).
} 
seria necessário enfrentar o paradoxo da concepção do processo de formação do sujeito de Foucault, que Butler incorporou em Problema de gênero. Esse paradoxo, segundo Butler, estrutura o debate sobre a capacidade de ação do sujeito produzido pelo poder que, por sua vez, expõe a ambivalência de seu processo de produção. Butler sintetiza essa ambivalência na seguinte questão:

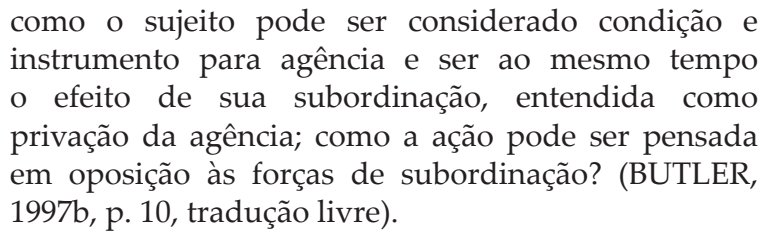

A fim de refutar as acusações de determinismo, Butler admite que precisa explicar a relação entre subordinação à norma e ação. Afinal, se é a norma que produz ao mesmo tempo em que subordina o sujeito, mas este último não é simplesmente determinado por ela, isso implica que haja alguma agência do sujeito no cumprimento da norma. No entanto, sua influência foucaultiana lhe leva a admitir que não há um sujeito anterior à norma que, ao mesmo tempo em que se subordina a ela, decide deliberadamente cumpri-la ou descumpri-la.

Escrevendo de uma perspectiva não iluminista, e pósliberatória (como diz a autora), Butler recusa a ideia de que haja um agente antes da ação. Mas, sendo assim, quem ou o que é o agente na relação com a norma? Que tipo de ação é possível no momento de submissão à norma, momento este que consiste no próprio processo de subjetivação? O problema de fundo aqui é: o que vem primeiro, o sujeito ou a norma? A resposta é Butler é:

Não há, por assim dizer, nenhuma transição conceitual a ser feita entre o poder como externo ao sujeito, que "age sobre", e o poder constitutivo do sujeito, "sobre quem a ação incide". O que se pode entender como 
forma de transição é na verdade uma ruptura, uma reversão constitutiva do próprio sujeito (BUTLER, 1997b, p. 15, tradução livre).

A reversão constitutiva do próprio sujeito remete à apropriação do poder pelo sujeito. O sujeito sobre o qual o poder incide não é o mesmo poder "exercido por ele". A apropriação do poder pelo sujeito não consiste numa operação que deixa o primeiro intacto. $\mathrm{O}$ ato de apropriação pode modificá-lo até o ponto de o poder do sujeito funcionar contra o poder que o constituiu. É assim que Butler compreende a resistência e responde às críticas de que em Problema de gênero ela teria "matado o sujeito".

No entanto, para chegar a essa concepção de resistência, Butler precisa explicar no que consiste essa apropriação, precisa explicar o processo de incorporação da norma pela psique do sujeito em formação. É por isso que Butler dedica todo um livro à tarefa de abordar a relação entre psique e poder. Em suas palavras:

\begin{abstract}
Se formas de poder regulatório são sustentadas em parte por meio da formação de um sujeito, e se essa formação ocorre de acordo com as exigências do poder, especificamente, com a incorporação das normas, então uma teoria da formação do sujeito deve descrever esse processo de incorporação, e a noção de incorporação deve ser interrogada a fim de se apurar a topografia psíquica que assume. Como a sujeição ao desejo requer e institui o desejo pela sujeição? (BUTLER, 1997b, p. 19, tradução livre, minhas ênfases).
\end{abstract}

Esse é o problema teórico que estrutura o livro The Psychic Life of Power. Nessa obra, Butler admite que terá de ir além de Foucault que, como diz ela, "era notoriamente taciturno no tópico da psicanálise" (BUTLER, 1997b, p. 18, tradução livre), pois o processo de subjetivação entendido como subordinação a uma norma por um sujeito (em formação) que a reitera exige que se investigue o processo de incorporação psíquica da norma. 
b) A melancolia e a incorporação da perda constitutiva

O processo de incorporação psíquica da norma, ao ser entendido como parte do processo de subjetivação, leva Butler a relacionar a produção da identidade e a exclusão política à incorporação da perda, mais precisamente ao que Freud chamou de melancolia.

Em $O$ Ego e o $I d$, Freud define melancolia como um o processo contínuo de luto pela perda de um objeto. Como o luto é contínuo, a vinculação com o objeto perdido também o é. O sentimento de perda torna-se, assim, permanente e se instala na psique humana através do processo de identificação. Desse modo, o objeto perdido é preservado como parte da própria psique. É isso que Freud chama de identificação regressiva (BUTLER, 1997b, p. 133). Assim, o objeto perdido coexiste com o próprio ego. Nós perdemos o objeto no mundo externo, mas suportamos essa perda porque é ela que nos provê a possibilidade de tornar permanente nossa vinculação com ele no mundo interno. Ou seja, só podemos desistir de um objeto porque temos o recurso da "incorporação melancólica" (ibid.).

Butler aproveita a identificação regressiva freudiana para interpretar a identidade de gênero. Ela afirma que as identidades "masculina" e "feminina" são estabelecidas através de proibições que impõem a perda de determinadas formas de viver a sexualidade e que reprimem o luto por essa perda (BUTLER, 1997b, p. 135).

Uma identidade de gênero coerente, que é indispensável para o reconhecimento social, pressupõe o cumprimento da norma da heterossexualidade. Ter o direito a uma identidade de gênero inteligível implica reprimir a melancolia da homossexualidade. Por isso, os vínculos homossexuais não apenas transgridem a heteronormatividade, eles têm o poder de corroer as categorias de gênero. A ameaça que representam não é externa, é interna. Trazem à tona a possibilidade de retomar o objeto perdido, mas um objeto de cuja repressão e esquecimento depende o reconhecimento social (BUTLER, 1997b, p. 136).

A heterossexualidade, portanto, torna-se natural pela rejeição da homossexualidade, uma vez que a identidade de 
gênero hegemônica é obtida pela incorporação melancólica da homossexualidade (BUTLER, 1997b, p. 137). Essa perda não pode ser externalizada e, por isso, ela se volta contra o próprio ego na forma de superego. A proibição do luto da homossexualidade forma nosso sentimento de culpa que é continuamente reforçado pelo superego.

A conduta social ideal é definida por oposição à homossexualidade; é um ideal que aparece concretamente nos padrões aceitos de família, de classe e de nação. Esse ideal incide tanto sobre aqueles que o realizam, quanto sobre aqueles que falham em realizá-lo, provocando nestes últimos um sentimento de inadequação e culpa (BUTLER, 1997b, p. 141). No entanto, a renúncia à homossexualidade e sua consequente internalização a reforçam na exata medida que a heterossexualidade é externalizada.

Trazer a identificação melancólica de Freud para o tema da identidade de gênero leva Butler a refletir sobre a ligação entre performatividade e melancolia, ou seja, sobre a relação entre a "perda constitutiva internalizada" e a "performance de gênero externalizada". Conforme já foi dito, em Problema de gênero, ela aponta a "drag queen" como um exemplo de performance subversiva em um mundo em que a heteronormatividade é a norma de gênero hegemônica. Mas em The Psychic Life of Power, Butler admitirá que dizer que o gênero é performado não é suficiente, porque isso implica reduzir a atuação psíquica do gênero àquilo que é exteriorizado na performance, desconsiderando-se as formas de rejeição e repúdio que organizam a performance de gênero. Por isso, Butler considerará indispensável para seu projeto explorar, com a psicanálise, a opacidade do inconsciente e a dinâmica psíquica da incorporação melancólica do gênero (BUTLER, 1997b, p. 144). ${ }^{5}$

\footnotetext{
${ }^{5}$ Butler admite aqui explicitamente a limitação de sua compreensão de gênero em Problema de gênero.
} 
| 258 |

Feminismo, identidade e exclusão política...

c) A resistência à subordinação

Butler retoma a concepção de interpelação de Althusser para tratar da resistência. Nesse autor, a resposta à interpelação implica reconhecer autoridade naquele que nos aborda. Um dos exemplos de Althusser mais conhecidos é o do policial que aborda uma pessoa na rua. Ao gritar "Ei, você!", o policial constitui a identidade daquele a quem se dirige. $\mathrm{O}$ policial encarna a autoridade e seu chamado é o esforço de disciplinar a conduta daquele que é abordado. Se o interpelado atender ao chamado, ele dará início ao processo performativo que constitui a identidade de subordinado à autoridade policial. Caso contrário, ou seja, se o interpelado não se voltar para responder ao chamado da autoridade, sua condição de subordinado não se consolida. A subordinação, portanto, requer que o interpelado reconheça a autoridade da norma. Mas esse reconhecimento é imprevisível. O disciplinamento é sempre apenas uma tentativa (BUTLER, 1997b, p. 95).

No entanto, para entender a motivação da resistência, ou seja, por que o sujeito resiste à interpelação, é preciso antes entender porque ele a atende. Para Butler, isso exige entender não apenas o processo de produção das identidades, mas também a necessidade de o sujeito de se vincular à norma, ou seja, é preciso entender sua vinculação à norma que lhe confere existência à medida que o subordina (BUTLER, 1997b, p. 104).

Seguindo Foucault, Butler afirma que qualquer identificação pode ser aproveitada para funcionar como crítica a essa mesma identificação. E isso, diz Butler, mesmo quando somos interpelados de forma desrespeitosa. A apropriação de uma injúria pode funcionar tanto como um instrumento de subordinação quanto de resistência. Termos utilizados para depreciar determinados grupos podem ser incorporados à linguagem desses mesmos grupos de modo a lhes dar um novo significado. Ressignificar uma injúria desconstrói seu conteúdo ofensivo (ibid.).

Quando respondemos a um chamado, mesmo que estejamos sendo ofendidos, nós adquirimos existência social. Nós somos identificados. Mas essa identificação é um efeito de nossa subordinação à norma. Nós somos apaixonadamente vinculados 
a esse chamado em razão de nosso desejo narcísico de existir. Mas para Butler essa vinculação à norma pode ser desestabilizada, uma vez que a própria estabilidade da norma se dá no processo de subjetivação. Essa desestabilização, porém, não deve ser entendida como uma negação do termo, uma vez que tal entendimento da desestabilização suporia um sujeito pré-constituído, anterior ao termo ofensivo. E, conforme já foi mencionado, Butler é bastante insistente e clara ao recusar o sujeito anterior à norma.

A desestabilização do termo ofensivo terá, por isso, de ser entendida de outro modo. Para a autora, a resistência à subordinação não se dá pela afronta à norma, mas sim por sua apropriação e utilização de modo que ao invés de consolidar seu significado hegemônico, o desestabiliza. Assim, uma injúria não implica necessariamente a cristalização de uma identidade desvalorizada, ela levanta também a possibilidade de desestabilizar a "vinculação apaixonada à subordinação sem o que a formação - e re-formação - do sujeito não pode suceder" (BUTLER, 1997b, p. 104, tradução livre).

A desestabilização de nossa vinculação apaixonada à norma parece ser, portanto, uma condição da resistência. Mas essa vinculação, segundo a própria Butler, não é facilmente vencível. Afinal, romper a cumplicidade com a norma disciplinar implica romper com a nossa necessidade narcísica de ter existência social.

Portanto, as opções que estão disponíveis para o sujeito parecem ser apenas duas: existir e se subordinar, ou resistir e sacrificar a própria existência. Em Butler, a resistência não exige que o sujeito rompa sua cumplicidade com a norma. Ela exige, sim, que este se volte contra a norma de modo a desestabilizar as relações de poder da qual emergiu. Isso exige uma vontade de "não ser". Mas por que o sujeito desejaria "não ser"? Em nome de que enfrentaríamos nossa necessidade narcísica de termos uma existência social? Sua resposta é a seguinte:

Nós devemos reler "ser" como precisamente a potencialidade que não é exaurida por nenhuma interpelação particular. Essa falha da interpelação pode 
$|260|$

Feminismo, identidade e exclusão política...

minar a capacidade de o sujeito "ser" em um sentido "autoidêntico", mas deve também marcar o caminho para uma forma de ser mais aberta, e mesmo mais ética, uma forma de ser do e para o futuro (BUTLER, 1997b, p. 131, tradução livre).

No entanto, conforme observa Amy Allen, essa resposta não é suficiente para que Butler escape do impasse que ela mesma cria ao estabelecer uma relação necessária entre dependência, reconhecimento e subordinação:

\begin{abstract}
se tornar-se um sujeito necessariamente envolve capitular à subordinação, então a resistência à subordinação implicaria a recusa de ser um sujeito, a recusa de capitular à lógica da subordinação. No entanto, se, conforme Butler disse, nossas únicas alternativas são a submissão à lógica da subordinação ou não ter existência social, então essa recusa corre o risco de ser uma forma de suicídio social que é indesejável em si mesmo e incompatível com a própria concepção de Butler de narcisismo primário, e de nosso desejo de reconhecimento, independentemente do preço que esse reconhecimento possa custar. Por isso, se seguirmos a lógica da análise da subordinação de Butler até sua conclusão natural, parece que chegaremos em um beco sem saída (ALLEN, 2008, p. 83). ${ }^{6}$
\end{abstract}

\footnotetext{
${ }^{6}$ É importante salientar que, em Butler, a participação ativa do sujeito no processo de sua formação não está respaldada na intencionalidade do agente. Essa participação se dá pela incorporação psíquica do poder pelo sujeito no processo de sua formação. E essa incorporação não é feita racional ou deliberadamente pelo sujeito. Amy Allen não discorda disso. Sua crítica a Butler não é uma cobrança de explicações sobre a origem de uma vontade deliberada de insubordinação. O ponto de Allen é o de que Butler explica o processo de vinculação psíquica do sujeito à norma e à subordinação, mas não oferece ferramentas para explicar a desvinculação psíquica do sujeito da necessidade narcísica de existir, uma desvinculação que a concepção
} 
A saída desse impasse, segundo Allen, requer uma distinção entre dependência e subordinação (ALLEN, 2008, p. 83), além da distinção normativa entre formas melhores e piores de construção da identidade, sem a qual a resistência suporia que o sujeito arrisca toda a sua possibilidade de ser reconhecido socialmente. Mas para isso Butler teria de articular (e colocar em discussão) um critério normativo para fazer essa distinção, uma tarefa que ela recusou firmemente ao longo de toda a década de 1990.

\section{2) Nancy Fraser: os pontos fracos e fortes de Problema de gênero}

Nancy Fraser compartilha com Butler alguns pontos importantes da relação que estabelece entre processo de subjetivação e poder, mas diverge dela no que se refere à sua recusa em explicitar o critério normativo que embasa sua crítica à exclusão.

Para esclarecer sua posição, Fraser distingue analiticamente dois aspectos no argumento de Butler em Problema de gênero, um ontológico, e outro normativo. Fraser assinala que Butler defende uma ontologia pós-estruturalista do sujeito, segundo a qual não é suficiente reconhecê-lo como construído por seu contexto, ele deve ser entendido como um produto do poder. Ao contrário do que pensam muitos dos opositores de Butler, diz Fraser, essa ideia não exclui a capacidade crítica do sujeito, ${ }^{7}$ mas apenas a concepção de autonomia que pertence a uma estrutura da subjetividade anterior às relações de poder.

de resistência que Butler oferece em The Psychic Life of Power parece exigir. Anos mais tarde, em 2004, a própria Butler admitirá que sua concepção de resistência requer "a suspensão das gratificações narcísicas que a conformação à norma provê"' (cf. BUTLER, 2004).

${ }^{7}$ Fraser observa que a linguagem de Butler "é profundamente anti-humanista" e assinala que "O que eu chamo de 'capacidade das pessoas', ela [Butler] descreve como 'as possibilidades do próprio poder' e como um 'processo de significação' impessoal” (FRASER, 1995, p. 67, tradução livre). 
No entanto, para Fraser, a capacidade crítica em Butler apresenta algumas limitações relevantes. Embora Butler refira-se à transformação social com uma conotação positiva, seu argumento, no entender de Fraser, não é capaz de formular critérios para distinguir a mudança boa da má, a progressista da conservadora, a opressora da emancipatória.

Segundo Fraser, ao se recusar a articular ou mesmo a admitir que sua crítica à exclusão esteja respaldada em um critério normativo positivo, Butler protege este último da discussão pública e, assim, o pressupõe como algo consensual (ainda que o faça inadvertidamente). Além disso, essa recusa lhe impede de combinar a crítica feminista "a novos arranjos sociais capazes de harmonizar conflitos atuais". E, sendo assim, questiona Fraser, "como 'nós' poderemos articular 'nossa' visão em termos suficientemente convincentes para persuadir outras mulheres - e homens - a reinterpretar seus interesses?" (FRASER, 1995, p. 71, tradução livre).

Para Fraser, Butler não pode responder a essas questões porque sua concepção de liberação das mulheres está focada na liberação da identidade, já que Butler entende esta última como necessariamente opressora. Disso decorre, diz Fraser,

que a critica desconstrutiva [...] torna-se o modo privilegiado de teorização feminista, enquanto a crítica normativa e reconstrutiva é entendida como normalizadora e opressiva. Mas essa visão é limitada para alcançar plenamente as necessidades de políticas liberatórias. As feministas realmente precisam fazer julgamentos normativos e oferecer alternativas emancipatórias. Nós não apoiamos "qualquer coisa que apareça" [...]. De fato, processos "desreificantes" e "reificantes" são dois lados da mesma moeda pós-fordista. Eles exigem uma resposta de dois lados. Feministas precisam tanto da desconstrução quanto da reconstrução, 
da desestabilização de significado quanto de a projeção de uma esperança utópica (FRASER, 1995, p. 71).

Buscando dar conta dos dois lados da "moeda pós-fordista", Fraser formula seu próprio critério normativo positivo no contexto de sua reflexão sobre justiça. Seu ponto de partida é diagnosticar dois tipos de reivindicação no mundo contemporâneo: as reivindicações de redistribuição, e as de reconhecimento. As demandas redistributivas referem-se à distribuição justa da riqueza. As demandas relacionadas ao reconhecimento, por sua vez, buscam evitar a assimilação de todos os modos de vida a uma cultura dominante, seja essa cultura referente ao modo de valoração de determinadas etnias, identidades sexuais ou diferenças de gênero (FRASER, 2003).

Fraser baseia-se no que chama que "paradigma popular" para analisar a diferença e as semelhanças entre redistribuição e reconhecimento. O paradigma popular é o conjunto de suposições sobre as causas e as soluções para as injustiças que são tacitamente pressupostas pelos atores sociais e políticos. Segundo esse paradigma, cada movimento social está relacionado a um tipo específico de demanda. As reivindicações distributivas estão atreladas a movimentos de classe, enquanto as políticas de reconhecimento são relacionadas a movimentos identitários, como o movimento feminista, o movimento de gay e lésbicas, o movimento negro etc. Sua intenção, porém, é desfazer essa associação. Fraser quer mostrar que a redistribuição e o reconhecimento não constituem paradigmas distintos. São apenas dois aspectos de um mesmo paradigma de justiça.

Fraser deixa claro, porém, que ao questionar a separação dicotômica entre reconhecimento e redistribuição não está reivindicando que ambos sejam amalgamados. Nem todo problema de redistribuição é reflexo da depreciação cultural. Como exemplo, ela descreve o caso do homem branco que trabalha 
em uma indústria e que fica desempregado depois do fechamento da fábrica. Aqui, a falta de redistribuição não pode ser reduzida ao problema da falta de reconhecimento. De outro lado, a falta de reconhecimento não pode ser reduzida à falta de redistribuição. Para esse caso, o exemplo de Fraser é o do banqueiro de Wall Street afro-americano que não consegue pegar um táxi (FRASER, 2003, p. 117).

As demandas de redistribuição e reconhecimento são distintas, mas elas se justificam em função de um mesmo princípio. Em ambos os casos, o remédio adequado para corrigir a injustiça deve estar orientado para a restituição da igualdade, independentemente de a desigualdade resultar de falta de redistribuição ou de reconhecimento.

A autora reconhece que alguns grupos sociais sofrem mais forte e frequentemente de falta de reconhecimento ou de falta de redistribuição. Em Justice Interruptus: Critical Reflections on the Postsocialist Condition, Fraser distinguiu injustiças de origem distributiva de injustiças por falta de reconhecimento. Mas em sua resposta às críticas de Iris Young e de Butler, ela assinala que todas as injustiças têm componentes de distribuição e reconhecimento. A diferença entre elas é apenas a causa que prevalece.

Iris Young e Judith Butler, cada uma a seu modo, opuseramse à justiça bidimensional de Fraser. Ambas a acusam de ter criado uma dicotomia entre a cultura e a economia. A preocupação de Butler é com a identificação do movimento de gays e lésbicas com demandas "meramente culturais". Para ela, movimentos que criticam a regulação da sexualidade desafiam também o funcionamento da economia política. Butler cita Engels para mostrar que a relação entre produção e reprodução é reconhecida mesmo na tradição marxista que, segundo ela, costuma reduzir as desigualdades sociais à dimensão material. Butler observa que Engels, em A origem da família, da propriedade privada e do Estado, sustenta que a produção dos meios de existência, do alimento, do vestuário, do abrigo e a própria propagação da espécie são précondições necessárias para a produção (BUTLER, 1997a, p. 271). 
Butler afirma que Fraser, ao definir o movimento de gays e lésbicas como tipo ideal de luta por reconhecimento, deixa de lado o interesse econômico na heteronormatividade como condição para a produção de uma população numerosa que atenda às demandas do sistema capitalista. A conexão entre sexualidade e economia política em Butler implica, portanto, a expansão da esfera econômica de modo a abranger tanto a reprodução de bens quanto a de pessoas (BUTLER, 1997a, p. 272). ${ }^{8}$

$\mathrm{O}$ argumento de Butler pode dar a impressão de que ela pretende substituir a identificação dos movimentos de gays e lésbicas com o reconhecimento pela identificação com a redistribuição. Mas não é esse seu objetivo. O seu ponto é, ao contrário, frisar que essa distinção não faz sentido. Não se trata, portanto, de saber se as políticas sobre sexualidade pertencem ao âmbito cultural ou econômico. O importante é reconhecer que as diversas práticas sexuais confundem a distinção entre ambos. Sua intenção, portanto, não é substituir o cultural pelo econômico, mas sim questionar essa distinção (BUTLER, 1997a, p. 275).

Fraser responde a Butler dizendo que as minorias sexuais são, sim, afetadas pela má distribuição, mas não do mesmo modo que os grupos cuja luta primordial é contra a exploração. Para Fraser, equiparar diferentes modos de má redistribuição pode levar à conclusão de que o remédio adequado para reverte todas as injustiças é o mesmo. Além disso, quando Butler propõe a desconstrução da distinção entre reconhecimento e redistribuição, ela perde a dimensão histórica necessária para uma teoria social, porque situa a ação e a crítica social em uma propriedade abstrata da linguagem, como a ressignificação e a performatividade. Ao invés disso, Fraser prefere privilegiar a tensão real nas relações sociais atuais, pois desse modo é possível identificar as motivações das lutas por justiça do presente (FRASER, 1997, p. 286).

\footnotetext{
${ }^{8}$ Butler observa que Gayle Rubin já havia chamado para isso quando afirmou que a reprodução normativa do gênero é uma exigência da reprodução da heterossexualidade e da família.
} 
Fraser afirma que uma amostra da abstração histórica do argumento de Butler está na sua ideia de que a regulação heteronormativa da sexualidade é econômica porque é condição para o funcionamento do capitalismo. No entanto, diz Fraser, o vigor do capitalismo contemporâneo não depende mais do aumento populacional. $\mathrm{O}$ heterossexismo não pode mais ser explicado dessa forma. Por isso, atualmente é mais razoável atribuir as desvantagens econômicas que gays e lésbicas sofrem a um reconhecimento deficiente (FRASER, 1997, p. 285).

Iris Young, como foi dito, também se opõe à distinção entre reconhecimento e redistribuição. Assim como Butler, ela acusa Fraser de definir a economia política e a cultura como categorias opostas e excludentes. Desse modo, diz Young, Fraser não abarca as injustiças dos grupos que sofrem injustiças tanto de reconhecimento quanto de distribuição. Ela acrescenta ainda que o modelo bidimensional de Fraser deixa de lado uma terceira dimensão da justiça: a política. Para Young, a dimensão referente às instituições e práticas da lei, cidadania e administração não têm espaço na teoria de Fraser.

Quanto ao fato de Fraser não reservar uma esfera para a política em sua teoria de justiça, talvez Young tenha razão. Um sinal disso é que Fraser, após os debates com Young, irá modificar sua concepção de justiça incluindo a representação como uma terceira dimensão da justiça, justamente a dimensão política. A dimensão política da justiça em Fraser levantará as seguintes questões: a) as relações de representação são justas? b) As normas decisórias de uma dada comunidade política garantem voz igual nas deliberações públicas a todos os seus membros? c) as fronteiras da comunidade política excluem grupos e pessoas que deveriam ser incluídos com status de cidadãos? (FRASER, 2009, p. 18).

Esses conjuntos de questões referem-se às duas dimensões da justiça política: a representação no plano da política local, e o que Fraser chama de mau-enquadramento. A primeira levanta debates sobre os diferentes sistemas eleitorais, bem como sobre o modo como as normas decisórias consideram as exclusões fundadas em desigualdades de gênero, raciais, orientação sexual e classe. Essas 
são questões pertencem à esfera da justiça política que geralmente se dá no âmbito da esfera nacional (FRASER, 2009, p. 19).

O segundo nível da justiça política corresponde àquele que justifica normas de exclusão e inclusão. São normas de meta-justiça porque definem os membros que a comunidade política levará em conta nos assuntos de distribuição, reconhecimento e representação política ordinária, nacional. As injustiças produzidas por esse tipo de exclusão são as que Fraser denomina "mau-enquadramento" (misframing). Trata-se de um tipo de injustiça similar àquela sofrida por pessoas excluídas do que Hannah Arendt chamou de "direito a ter direitos". A privação desse direito seria um tipo de "morte política", uma vez que a impossibilidade de protagonizar reivindicações normativas tornaria aqueles que deveriam ter status de cidadãos "não pessoas em relação à justiça" (FRASER, 2009, p. 19-20).

No entanto, se Young parece estar correta em apontar o déficit político na primeira versão da concepção de justiça de Fraser, a crítica de Young à suposta separação dicotômica entre cultura e economia parece perder de vista um ponto que Fraser insiste em salientar. O reconhecimento e a redistribuição são duas dimensões de um mesmo paradigma de justiça. São distintos, mas estão fortemente relacionados. Não apenas nos grupos que denomina bidimensionais, como raça e gênero, mas também nos demais. A razão pela qual Fraser mantém a distinção está no fato de entender que os remédios para cada tipo de demanda são distintos.

Em livro escrito em parceria com Axel Honneth, ela chega a afirmar que todos os grupos que sofrem injustiças sociais são bidimensionais, ou seja, sofrem de falta de reconhecimento $e$ redistribuição. No entanto, ela cita os grupos de gênero e raciais como os casos típicos de bidimensionalidade, ou seja, como grupos em que o grau da (má) redistribuição e de (pouco) reconhecimento estão mais equilibrados do que em grupos de minorias sexuais ou grupos de operários. Nestes dois últimos casos, a tônica da demanda está no reconhecimento e na redistribuição, respectivamente (FRASER, 2003, p. 128). 
| 268 |

Feminismo, identidade e exclusão política...

No caso do gênero, a injustiça na distribuição de recursos é um elemento forte da desigualdade porque o gênero funciona como um princípio organizador da estrutura econômica da sociedade capitalista. A divisão entre trabalho produtivo (remunerado) e trabalho reprodutivo (não remunerado), associados respectivamente ao masculino e ao feminino, estão na base de desigualdades materiais. Além disso, o gênero também implica diferenciação de status, uma vez que os padrões culturais institucionalizados privilegiam características associadas à masculinidade (FRASER, 2003, p. 23).

A raça também constitui grupos tipicamente "bidimensionais". É possível identificar um padrão racial na pobreza. Imigrantes, minorias étnicas e afro- descendentes são em geral as principais vítimas da pobreza e do desemprego. Além disso, esses grupos sofrem também de desvalorização de sua identidade em razão de padrões culturais eurocêntricos institucionalizados que depreciam não brancos (FRASER, 2003, p. 23).

A raça e o gênero, enfim, são os exemplos típicos de subordinação bidimensional. Isso não significa que operários e minorias sexuais não estejam sujeitos às injustiças de reconhecimento e redistribuição, respectivamente. Mas apenas que as classes sociais são dividas por critérios principalmente distributivos, e as minorias sexuais, por critérios principalmente identitários. Toda injustiça demandará sempre as duas medidas, até porque os eixos de subordinação estão todos entrecruzados. A sexualidade, a classe, a raça e o gênero combinam-se de inúmeras formas distintas, e em muitas dessas combinações, as injustiças se acumulam. Assim a dosagem do remédio para a injustiça somente poderá ser definida empiricamente (FRASER, 2003, p. 25).

Em suma, em Fraser, integrar reconhecimento e redistribuição não significa fundi-los em um único conceito. Sua proposta é manter essa distinção analítica, mas sempre condicionar a validade das demandas por reconhecimento a um princípio de justiça igualitário. Isso não implica deslegitimar as demandas de reconhecimento, mas sim os argumentos que as justificam em 
nome do direito à diferença. Para Fraser, políticas de identidade são problemáticas porque a afirmação da diferença tende a ser excludente. Daí seu argumento de que é preciso incorporar a desconstrução da identidade, tal como formulada por Butler, à demanda feminista (FRASER, 2003, p. 106 e 2007a, p. 107).

Isso significa recusar totalmente o reconhecimento das particularidades? Nem sempre. Fraser defende que a ênfase no reconhecimento ou na redistribuição depende da injustiça que deve ser corrigida. No caso do apartheid na África do Sul, por exemplo, a ênfase teve de ser no reconhecimento. No entanto, o remédio adequado para garantir o reconhecimento não esteve focado na valorização da identidade negra, mas sim na cidadania universal não-racializada (FRASER, 2007a, p. 122).

A afirmação de que todas as particularidades ameaçam a igualdade ou de que toda igualdade coloca em risco a identidade é fruto de uma análise descontextualizada da desigualdade. Conforme o caso, as desigualdades terão de ser corrigidas ora pelo reconhecimento da diferença, ora pela preservação da igualdade. Por isso, conclui Fraser, deve-se admitir que o reconhecimento das particularidades pode, sim, ser legitimado. Mas isso deve ser feito não em nome da identidade, mas sim da igualdade, mais precisamente da igualdade de participação política (ibid.).

Isso significa tratar o reconhecimento como uma questão de status. Tratar o reconhecimento dessa forma implica relacionálo ao modo como as instituições valoram a condição dos atores sociais. A falta de reconhecimento, portanto, será detectada pela desvalorização de determinados atores pelas instituições. Fraser cita como exemplo de falta de reconhecimento a proibição do casamento entre pessoas do mesmo sexo, políticas de bemestar social que estigmatizam mães-solteiras como sexualmente irresponsáveis, e práticas de policiamento que pressupõem que determinados grupos raciais são mais propensos a praticar crimes (FRASER, 2007a, p. 108).

Todas essas discriminações exigem políticas de reconhecimento, mas, segundo Fraser, isso não precisa e não deve 
ser feito a partir de políticas de identidade. Garantindo aos atores estigmatizados a condição de parceiros integrais na interação social, o reconhecimento é assegurado. A política de reconhecimento deve ter por finalidade a superação da subordinação, e não a valorização do particular. A luta pelo reconhecimento, portanto, é a luta pela desinstitucionalização da desvalorização de determinados grupos, que os impede de participar como iguais de seu grupo social (FRASER, 2007a, p. 109).

Além de rejeitar concepções de reconhecimento com foco na diferença, Fraser também se opõe a teorias que justificam políticas de reconhecimento com base nos danos na estrutura psíquica dos indivíduos causados pela discriminação. Para Fraser, "a falta de reconhecimento é uma relação social institucionalizada e não um estado psicológico". Em seu debate com Axel Honneth, ela afirma que Honneth privilegia este último aspecto em detrimento do papel que as instituições cumprem na inclusão social. Essas investigações, diz Fraser, podem levar a substituir "a mudança social por formas intrusas de engenharia da consciência" (FRASER, 2003, p. 28, tradução livre).

Fraser teme que, explorando-se a dimensão psíquica do déficit de reconhecimento, se termine responsabilizando a própria vítima da discriminação pela injustiça que sofre. Afinal, considerar que a falta de reconhecimento gera um "dano psíquico" pode estigmatizar ainda mais os grupos oprimidos. Além disso, se o não reconhecimento implica a internalização do preconceito pelo próprio discriminado, a política de reconhecimento teria de reverter a autodepreciação impondo algum modo de autovalorização. Teria de impor concepções de bem aos grupos discriminados. Para Fraser, isso é autoritário. Com isso, ela não pretende negar que a falta de reconhecimento produza efeitos psicológicos. Ela diz apenas que a solução disso independe desses efeitos, e nem deve agir sobre eles (FRASER, 2003, p. 114).

Portanto, a fim de evitar que os remédios para sanar injustiças produzam "reengenharias da consciência", Fraser descarta a dimensão psíquica do processo de subjetivação como um nível de análise na produção de diagnósticos da opressão. 
No entanto, a meu ver, esse descarte é bastante limitador em qualquer diagnóstico de injustiça, a ainda mais problemático no caso das injustiças de gênero, uma vez que sua manifestação é historicamente carregada de ambiguidades. Ao menos desde que Beauvoir escreveu sobre as "delícias da passividade", uma das passagens mais polêmicas de $O$ segundo sexo, a ambiguidade da opressão da mulher apresenta-se como um elemento importante para o diagnóstico da opressão de gênero.

Essa ambiguidade pode ser ilustrada por uma pesquisa sobre distúrbios alimentares realizadas com estudantes mulheres de um curso sobre Estudos de Gênero na Universidade de Cornell. Segundo essa pesquisa, nesse curso havia um número alto de alunas que sofria de bulimia e anorexia. O perfil das alunas era de pessoas engajadas política e teoricamente com o feminismo, com um discurso bem articulado contra a padronização e regulação dos corpos femininos. Apesar disso, a maior parte delas declarou que não conseguia controlar o impulso de seguir esses padrões até o ponto de sofrerem de distúrbios alimentares (BRUMBERG, 1997 apud ALLEN, 2008, p. 181).

De onde vem o impulso de seguir esses padrões de subordinação entre pessoas que articularam o discurso crítico à opressão de gênero? Ou, como diz Allen, o que a persistência da adesão a padrões opressores, mesmo entre feministas, nos diz sobre como devem ser as práticas de resistência individual, e sobre como se dá a transformação da sujeição?

Fraser não tem uma resposta para esse tipo de questão, nem tampouco esteve ou está disposta a considerar essa pergunta como um problema teórico-político. De fato, ao longo de sua obra, Fraser é tão persistente na crítica à política de identidades quanto na recusa em articular política e psicologia.

Em relação à crítica à política de identidade, Fraser é fortemente influenciada por Butler, mas, no que se refere à relação entre política e psicologia, a distância entre as autoras é evidente. Afinal, Fraser não recusa apenas o argumento de Butler em relação ao modo como combina subordinação, resistência e reconhecimento 
em The Psychic Life of Power. Ela recusa o próprio problema teórico que estrutura esse tipo de investigação. E ao recusar esse problema teórico, fica sem instrumentos para abarcar em seus diagnósticos as ambiguidades da opressão de gênero.

\section{Considerações finais}

Quais são, então, os pontos cegos em Butler e Fraser que o debate entre as autoras contribui para iluminar? A insistente cobrança de Fraser a Butler no sentido de formular e explicitar o critério normativo que embasa sua crítica à exclusão revela que a crítica desconstrutiva de Butler está carregada do preconceito pós-estruturalista em relação a critérios normativos, entendidos invariavelmente como regulação. E esse preconceito limita a possibilidade de se vislumbrar e justificar no espaço público arranjos sociais mais justos. Afinal, sem explicitar o critério normativo por trás da crítica desconstrutiva, não há como diferenciar, justificadamente, relações sociais mais ou menos opressoras. E, como diz Fraser, o movimento e a teoria feminista precisam ter critérios para fazer essa distinção, pois não estão nem nunca estiveram dispostos a apoiar qualquer novo arranjo que apareça depois de reconfigurações das relações de poder.

A obra de Butler, por sua vez, traz à tona o déficit psíquico no diagnóstico de Fraser. Na obra de Fraser, à semelhança de Foucault, a psicologia aparece como prática discursiva que leva à sujeição. Mas, como diz Ferrarese,

A descrença de Fraser em abordagens psicológicas [...] não decorre de simples resistência em relação às ambições hegemônicas do discurso psicológico relacionado à situação da mulher ou a formas possíveis de sua emancipação. Ela está baseada na convicção de que política e psicologia são incompatíveis de algum modo. Quando a psicologia está no primeiro plano, a política se dissipa no segundo plano (FERRARESE, 2015). 
No entanto, a incompatibilidade entre política e psicologia na obra de Fraser a deixa presa ao paradoxo que a própria Butler reconheceu em Foucault. Se o sujeito produzido pelo poder não é determinado por ele, se há agência no processo de subjetivação, conforme Butler sustenta (e Fraser subscreve), é preciso compreender o processo de incorporação psíquica da subordinação. Esse é um passo indispensável para que se dê conta tanto da agência na subordinação, quanto da resistência que emerge das mesmas relações de poder que subordinam. Ao corroborar a ontologia de Butler, e evitar a exploração da vida psíquica do poder, Fraser fragiliza seu diagnóstico da opressão, pois fica sem ferramentas para abarcar as ambivalências da motivação da crítica. E sem essas ferramentas, o risco de estigmatizar os grupos oprimidos como covardes, fracos e passivos, que é justamente o que Fraser quer evitar ao separar psicologia e política, é ainda maior quando estas últimas são entendidas como incompatíveis.

\section{Referências}

ALLEN, A. The Politics of Ourselves: Power, Autonomy and Gender in Contemporary Critical Theory. New York: Columbia University Press, 2008.

BUTLER, J. Bodies that Matter: On Discursive Limits of Sex. Nova York: Routledge, 1993. 1997a.

Merely Cultural. Social Text, vol. 13, n. 52-53, p. 265-77,

The Psychic Life of Power: Theories in Subjection. Stanford: Stanford University Press, 1997b.

Bodies and Norms Revisited. In: TAYLOR, D.; VINTGES, K. (orgs.). Feminism and the Final Foucault. Urbana: University of Illinois Press, 2004, p. 183-194.

Gender Trouble: Feminism and the Subversion of Identity. Nova York, Londres: Routledge, 2007 [1990]. 
CYFER, I. A tensão entre o feminismo moderno e pós-moderno na crítica à exclusão do feminismo. Tese (Doutorado em Ciência Política), Universidade de São Paulo, Faculdade de Filosofia, Letras e Ciências Humanas, São Paulo, 2009.

FERRARESE, E. Nancy Fraser and the Theory of Participatory Parity, Books and Ideas, 14/09/2015. Disponível em: <http:// www.booksandideas.net/Nancy-Fraser-and-the-Theory-ofParticipatory-Parity.html>. Acesso em: 05/02/2017.

FRASER, N. False Antitheses: A Response to Seyla Benhabib and Judith Butler. In: BENHABIB, S.; CORNELL, D.; BUTLER, J.; FRASER, N. Feminist Contentions: A Philosophical Exchange. New York, London: Routledge, 1995, p. 59-74.

Heterosexism, Misrecognition and Capitalism: A Response to Judith Butler. Social Text, vol. 13, n. 52-53, p. 279-89, p. 1997.

. Rethinking Recognition, New Left Review, 3, p. 107-20,

2000.

Mapeando a imaginação feminista: da redistribuição ao reconhecimento e à representação. Revista de Estudos Feministas, vol. 15, n. 2, p. 291-308, 2007a.

Reconhecimento sem ética?. Lua nova, 70, p. 101-38,

$2007 b$.

Scales of Justice. Nova York: Columbia University Press, 2009.

FRASER, N.; HONNETH, A. Redistribution or Recognition: A Political-philosophical Exchange. Nova York: Verso, 2003.

JUDITH BUTLER, philosophe en tout genre. Direção: Paul Zajdermann. Arte, 2006. Disponível em: <https://www.youtube. com/playlist?list=PL4EC66D573ED68FA1>. Último acesso em: 05/02/2017. 